\title{
The Control System and Performance: The Approach of Interaction and System for Contingencies in Management Accounting Research
}

\author{
Irma Ibrahim \\ Department of Economic Science Universitas Muhammadiyah Maluku Utara, KH. Ahmad Dahlan 100 Ternate City, Indonesia
}

\begin{abstract}
This study was conducted to determine the effect of the control system on the company's performance, which involve uncertainty perceived environment (PEU). Using interaction and a system approach, which is used to test compatibility between contextual variables and organizations, to test the hypothesis. Therefore, this study has the meaning of theoretical and methodological. Data was collected from manager of Rural Banks (BPR), where the Branch of Indonesia Central Bank in Makassar had supervised them. There were 97 samples collected using a mail survey and selected by purposive random sampling. Variables included PEU, control systems and financial performance. According to the previous literature, the control system is categorized into operational control systems, control systems management and strategic planning, while the financial performance measured by ROA. The results showed that the control system affect the financial performance, which involve PEU and using a systems approach. Anyway, based on this research, systems approach is better than the approach of interaction.
\end{abstract}

Keywords: Control systems, perceived environment uncertainty, interaction approach, system approach, performance.

\section{Introduction}

The control system is a key area of the company. The control system is defined as all procedures and formal systems that use information to maintain or change the pattern of activity of the organization (Simons, 1987). The control system with regard to strategies to achieve goals that are measured on organizational performance (Anthony and Vijay G., 1998).

Previous research showed that the application of the system to effectively control the organization will provide a significant impact on performance improvement. However, the relationship is not directly so, but there are contextual factors (eg, environmental uncertainty (PEU)) that exists in the relationship between the control system with the organization's performance (Chong VK, 1996).

Arguments in favor of the proposition is the fact that the environment is an important contextual factors that have a strong impact on company performance. Furthermore, in the case of contingencies stated that organizational effectiveness is a function of the fit (compatibility) between the organizational structure and the environment in which it operates (Duncan and Ken Moores, 1989). Studies that examine the relationship between the control system with the performance of an organization involving contextual variables have been well recognized by researchers as the application of contingency theory. Contingency approach is an application of the concept of the theory that there is no control system is the best that can be applied to all organizations and the implementation of appropriate control systems should see their involvement contextual variables where the organization is located.

Studies conducted by Otley (1980) on the results of research Gordon and Miller (1976), Dermer (1977), Waterhouse and Tiessen (1978), Burn and Waterhouse (1975) and Hayes (1977) and Piper (1977) showed that, research this is very little use-organization theory literature and even there are some deviations from organizational literature. The deviation is due to the design of contingency framework, especially in the aspect of testing methods.

Furthermore, Fulmer and Rue (1974), Kenis (1979), Boulton (1982), Simons (1987), Mark (1989), Moers and Hartmann (1999), Shield et al, (2000) Chong VK, et al (2001), VK Chong and Chong KM (2004) shows the importance of the involvement of contextual variables in the relationship between the control system with the performance of the organization. Contingency approach is an important breakthrough that could shift the universalistic approach (Bays, 2000; Duncan and Keith, 1989; and Drazin and Van de Ven, 1985).

The problem, previous empirical research in the field of contingencies showed characteristic testing the relationship between the variables in the model simple contingencies and unpatterned (Fry and Smith in Duncan and Ken Moores, 1989). Correspondence between contingency variables with the organizational variables, the research built on the proposition that the relationship is different, though, the central concept of a contingent proposition is fitted, which is a match between the contextual variables with organizational design. In this case, Drazin and Van de Ven (1985) later reported their conceptual approach regarding fit. According to them, there are at least three different approaches in measuring the fit between organizational variables and variable contingencies. The third approach is to approach selection, interaction approach and system approach.

The selective approach assumes fit as correspondence (congruence) between contextual variables to the organizational structure, such formalization and centralization. But this approach does not explicitly test the effect of contextual variables with the relationship between organizational performance. Interaction approach, assuming 


\section{International Journal of Science and Research (IJSR) \\ ISSN (Online): 2319-7064}

Index Copernicus Value (2013): 6.14 | Impact Factor (2014): 5.611

the concept of fit as bivariate interaction. Fit is the interaction of contextual variables-organizational which may have an impact on performance. In its development, the interaction of many approaches applied by the researchers using two concept analysis, multiple interaction and residual analysis.

However, there are differences of opinion regarding the validity of the use of sharp two concepts above. The difference between the results of research and Werbel Dewar (1979), Duncan and Moores (1989), Frank Hartmann and Moers (1999), Mark (1989), Bambang RJ (2001) and Muhammad Jafar S. (2001) are proof enough of the this matter.

The third approach is an approach fit in a test system, which assumes a fit as the consistency of various contingency variables and organizational variables that have an impact on performance. In other words, the systems approach is an approach that applies contextual variable-organizational relationships simultaneously in a system that may be implicated in performance improvement. But so far, there has been little research that uses this approach.

Basing on the description above, this study specifically evaluated the use of a variety of approaches in research trials contingencies. The approach to be tested include the use of the concept of multiple regression and residual analysis in interaction approach, and the use of the concept of distance in a systems approach. This study did not look at the selection as an alternative approach to test this approach given the lack of clarity in research contingencies, as previously described.

Theoretically, this study wanted to test the effect of contextual variable's relationship (PEU) with organizational variables (control system) on the financial performance of the organization. In line with the idea of Anthony (in Mak, 1989) and outlook Veliyath, et al (1997), the control system as a variable organizational divided into three levels, namely the operational control system (OCS), management control system (MCS) and strategic planning (SP).

\section{State of the Problem}

So far, the contingency criticism directed more research in order to design contingency, especially in the aspect of testing methods. Drazin and Van de Ven (1985) proposes three important approaches in research contingencies, including: selection, interaction and systems. The fact that the approach to the selection and interaction gave rise to a number of weaknesses in both concept and consequences of the result, the direction of approach and then focused on a systems approach. Referring to the empirical facts and background of the research that has been mentioned above, the problem in this study can be formulated as follows; among the approaches and interaction system in a test fit, estimated is the best approximation of the methodological and theoretical standpoint. Theoretically, to test the effects of the multi - dimensional relationship between the variables OCS, MCS and SP with variable PEU, to company performance

\section{Methodology}

\section{Population and Sample}

The population in this study is the CEO or manager-level people's credit banks (BPR) located in South Sulawesi and is registered in the branch office (KC) Bank Indonesia (BI) Makassar. Selection of bank BPR as objects for their ability to survive in conditions of the crisis that began in early 1997 (Joko Sudarsono, 1999).

Between the branch office of Bank Indonesia, which is (3 branches), Makassar branch oversees 64\% of BPR throughout South Sulawesi, and is therefore expected to meet representation of the samples taken. On the other hand, the influence of confounding factors influencing also considered in the design of the sample.

Samples were taken by using purposive random sampling, sample RB healthy criteria based ROA amounted to $1.215 \%$ (BI Makassar, 2000). Sampling was done by mail survey of 160 respondents in the sample. A total of 102 samples returned for a response rate of $63.75 \%$. Total 102 samples, 5 samples did not meet the criteria, so it is used only 97 samples analyzed.

\section{Operational Definition of Variables}

The variables in this study included three main variables, namely in the form of contextual variables PEU and organization of OCS, MCS, and SP, and the variable results in the form of financial performance (ROA).

\section{Data Analysis Techniques}

The interaction of multiple approaches to test hypotheses 1 , referring to the equation (1). In this regard, a comprehensive statistical test design is as follows:

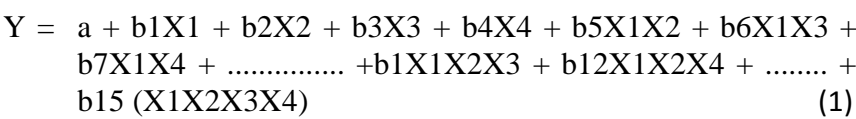

Where:

$\mathrm{Y}=$ Performance, $\mathrm{ROA}$

$\mathrm{a}=$ constant

b1..15 = Regression coefficient of X1 to the highest order (X1X2X3X4)

$\mathrm{X} 1, \mathrm{X} 2, \mathrm{X} 3$ = OCS, MCS, SP.

$\mathrm{X} 4=\mathrm{PEU}$

$\mathrm{X} 1 \mathrm{X} 2 \mathrm{X} 3 \mathrm{X} 4$ = Interaction Oder to four (four-way interaction)

Residual analysis approach to test the hypothesis 2, referring to the equation (2) and (3). In this case comprehensively statistical test design is as follows:

\section{Stage 1}

$\mathrm{Yi}=\mathrm{a}+\mathrm{b}(\mathrm{X})+\varepsilon \mathrm{y}$

Where,

$\mathrm{Yi}=$ The control system to $\mathrm{i}(\mathrm{OCS}, \mathrm{MCS}, \mathrm{SP})$

$\mathrm{a}, \mathrm{b}=$ constants and regression coefficient

$\mathrm{X}=\mathrm{PEU}$

$\varepsilon i=$ residuals from a regression to the control system to the $\mathrm{i}$ of the PEU. 


\section{International Journal of Science and Research (IJSR)}

ISSN (Online): 2319-7064

Index Copernicus Value (2013): 6.14 | Impact Factor (2014): 5.611

\begin{abstract}
Stage 2
$\mathrm{Y}=\mathrm{a}-\mathrm{b} 1|\varepsilon \times 1|-|\varepsilon \times 2| \mathrm{b} 2-\mathrm{b} 3+\varepsilon|\varepsilon 3|^{\prime}$

Where:

$\mathrm{Y}=\mathrm{a}$ performance, bi: constants, coefficients for i from

| $\varepsilon \mathrm{i}|| \varepsilon 1 . .3 \mid=$ the absolute value of residual OCS-PEU, MCS-PEU and SP-PEU

$\varepsilon$ ': random error (residual from equation (2)
\end{abstract}

The concept of distance from a systems approach to test the hypothesis 3, referring to the equation (4). In this case comprehensively statistical test design is as follows:

DIST $=\sqrt{ }\left(\sum\right.$ (xis - xis $) 2$

Where :

DIST = Euclidean distance from the point score $(\mathrm{j})$ to the ideal point i

Xis = score of the ideal type of the dimension (s) of contextual variables or organizational.

$\mathrm{Xij}=$ the real score to $(\mathrm{j})$ the dimension (s) of contextual variables or organizational.

Source : (Drazin dan Van de Ven, 1985; NIST, 2004)

\section{Results and Discussion}

Descriptive statistics, validity, and reliability of descriptive statistics, validity and reliability of variable instruments used to obtain the data was analyzed. Based on the result, it can be explained that for the primary data (PEU, OCS, MCS, SP) average price of goods at the top level 4 . This means that the respondents consider the contextual factors as the uncertainty factor that has a medium-high, and the average respondent to implement an advanced control system (advanced). $|\mathrm{z}|$ value 1.96 indicates that normal data for all variables. All measuring devices are also valid and reliable over 0.6 (Nunnally, in Ghozali, 2002).

\section{Test of hypothesis 1}

Hypothesis 1 in this study was tested with several models of interaction to show moderation PEU variables influence variables OCS, MCS and SP on financial performance (ROA). With the application of the equation can be stated that the first hypothesis is rejected with reference to test results. P-values are $\beta 150167$ with a value of $t=1,394$. Therefore, it can be concluded that with the approach of some interaction, PEU does not moderate the influence of OCS, MCS and SP on performance. An alternative approach multiple interaction is the absolute price difference between the value of contextual independent variables. To Cut and Shearon (1991), for example, designing the interaction model by defining (reducing) score locus of control on budget participation.

Thus the design due to the nature of the relationship between the dimensions (variables) that exist. Declared by Frocut and Shearon (1991) that the locus of control were associated with lower participation in the budget, and this has resulted in improved performance. Thus the model revealed by Venkatraman (2003) as fit matching (fit as a match) and open it suitable as an interaction (fit interaction).
Test of hypothesis 2

Another alternative approach to interact with the design of the fit is residual analysis (Duncan and Moores, 1989; Dewar and Werbel 1979, Mak, 1989). This approach applies not worthy of the absolute value of the results of the first phase of the regression residuals between the control system variables of the PEU. The values are not worth the setback simultaneously on performance as outcome variables (equation 2 and 3). The results of this study indicate that fit deviation ICS, MCS and SP against the European Union has no effect on the company's performance.

The result shown, VIF each $\varepsilon$ indicate a value of about 1 (under 10), which means there is no multicollinearity in the equation. Likewise to detect heteroscedasticity with Glejser test shows that the p-value $|\varepsilon i|$ regression to $\left|\varepsilon^{\prime}\right|$ nothing significant, which means that the model homoscedastic. Based on these facts, the resulting model is the best model despite showing rejection of the hypothesis.

On the other hand, although the deviation between PEU-SP ( $|\varepsilon 3|$ ) shows the p-value is significant at the 0.1 level, but the sign (sign) of the variable is not in line with expectations in the hypothesis. Duncan and Moores (1989), Dewar and Werbel (1979), Mak (1989), Drazin and Van de Ven (1985), indicate that the residual value is not worth the contextual variables and organizational relationships. This shows that the correlation between the performance is not eligible to be formed through a negative relationship in perspective contingencies.

These results are consistent with the results of Mak (1989) which concluded that the residual analysis approach, PEU does not moderate the influence of OCS, MCS, and SP in financial performance. However, this study is consistent with the findings of Duncan and Moores (1989) and Dewar and Werbel (1979).

\section{Test of hypotheses 3}

The testing hypothesis 3 of this study conducted in three stages. First, the determination of the ideal score of variations in organizational and contextual dimensions that will be tested in this study. Second, by applying equations and the ideal score for a dimension of the PEU, OCS, MCS and SP (respectively 70, 35, 49 and 49) can be calculated value within a specific company values the ideal score for each variable is determined by the value the highest that can be achieved for each combination of variables in each dimension (Bambang Riyanto, 2001). Thus, for PEU with item number 10 and the maximum scale of 7 , has a base value of 70 . Based on the obtained distance value, the last step is to correlate (or deterioration) performance score range (ROA).

Based on the result, it can be seen that the value $\beta$ for Distance whole variables significant at p-value 0.023 (0.05), with a negative sign. This shows that the distance between the PEU-OCS-MCS-SP affect the performance (ROA). Specifically, it can be stated that in the perspective of contingency performance is influenced by the interaction PEU with organizational variables: OCS, MCS and SP. 


\section{International Journal of Science and Research (IJSR) \\ ISSN (Online): 2319-7064}

Index Copernicus Value (2013): 6.14 | Impact Factor (2014): 5.611

Furthermore, these results support the conclusion Drazin and Van de Ven (1985) and the investigation of Bambang RJ (2001). In addition, the test results show that this model heteroskedastisitas homoskedastis.

Furthermore, simple regression test between each distance PEU-OCS, PEU and PEU-MCS-SP with the performance (ROA) showed a significant result for all the variables at the level of 0:05.

The results showed that the systems approach describes the reality of the relationship between dimensions. This is because that the empirical perspective, the relationship between the various variables in the organization with variable dimensions in which systemic and contextual dimensions simultaneously. the relationship between the various variables in the organization with variable dimensions in which systemic and contextual dimensions simultaneously. the relationship between the various variables in the organization with variable dimensions in which systemic and contextual dimensions simultaneously. The relationship between the variables between contextual and organizations that happens in space, which allows the combination of variables in patterns more systematic and structured which has implications for organizational performance.

\section{Conclusion}

In the perspective of a systems approach, perceived environmental uncertainty (PEU) and accounting control system, in this case the Operational Control System, System Management Control and Strategic Planning, affect the company's performance (ROA).

The relationship between the various variables in a contextual dimension - organization can be explained by the contingency theory by using an approach fit through some interaction, residue analysis and systems. In this case, the systems approach is better recognized in researching the relationship between contextual dimension-organization.

Specifically, this study cannot reject the hypothesis 3 . However, the failure to prove the hypothesis 1 and 2 does not mean the failure of contingency theory in explaining the phenomenon of organizational variables and contextual relationship, but due to the weakness of the approach used contingency theory test (multiple interaction and residual analysis).

This study has limitations in measuring the performance of a sample of companies. It is because of this study apply empirical data from the banking industry (BPR), which is generally determined based on the performance measures CAMEL, and not the ROA. On the other hand, in-depth study more to be done on samples of the manufacturing industry, which has a higher complexity of the control system.

\section{References}

[1] Bambang Riyanto LS., (2001) Alternative approach to examining a contingency model in accounting research: a comparison, Journal of Business and Accounting, vol. 1 No. 1, February, pp. 12-32.

[2] Bank Indonesia, (1999) Information in the field of banking regulation, September, BI-Semarang.

[3] Chenhall, R.H. (2003) Management control systems design within its organizational context: Findings from contingency-based research and Reviews directions for the future, Accounting, Oreganizations and Society, 28 (2-3), pp. 127-168.

[4] _ and D. Morris, (1986) The impact of structure, environtment, and interdependence on the perceived usefulness of management accounting systems, the Accounting Review, January, pp. 16-35.

[5] Chong, Vinchent K., (1996) Management Accounting System (MAS), Task Uncertainty and Managerial Performance: A Research Note, Accouting organisasi and society, Vol. 21, No. 5 PP.115-121.

[6] _ Ian RC Eggleton, Michele Leong, (2001) "The impact of market competition and budgetary participation on performance and job satisfaction: Evidence from the Australian banking and financial services sectors, Working Paper, January, Department of Accounting and Finance, Faculty of Economics and Commerce, The University of Western Australia, Western Australia.

[7] __ And Chong KM (2004) An Examination of the Effects of the otivational and Informational Roles of Budget Participation on Performance, Working Papers, Department of Accounting and Finance, Faculty of Economics and Commerce, The University of Western Australia.

[8] Dewar, Robert, and James Werbel, (1979) Universalistic and contingency predictions of employee staisfaction and conflict, Adminstrative Science Quartelrly, September, Vol. 24.

[9] Drazin, R and AH Van De Ven (1985) Alternative Forms nof Fit in Contingency Theory, Administrative science quartely, 30, pp. 514-538. Duncan, Keith, and Ken Moores (1989) Residual analysis: a better methodology for contingency studies in management accounting, Journal of Management Accounting Research, Vol 1, Fall.

[10] Frucot, V., W.T. Shearon, (1991) Budgetory participation, locus of control, and Mexican managerial performance and job stisfaction, The Accounting Review, vol. 66. No. 1, pp. 80-99.

[11] Gordon, L.A., and D. Miller, (1976) A contingnecy framework for the design of accounting information systems, Accounting, Organizations and Society, pp. 59-69.

[12] _ And V.K. Narayanan (1984) Management accounting systems, Perceived environtmental and organisasi structure: an empirical investigation, Accounting, Organizations and Society, pp. 34-47.

[13] Gregson, Terry, et al., (1994) Role ambiguity, role conflict, and perceived environtmental: are the scale masruring separate construct for accountant, 
Behavioral Research in Accounting, Vol. 6, pp. 144159.

[14] Joko Sugiarsono, (1999) banks are small and medium enterprises, SWA, No. 22 / XV / 4-17 November.

[15] Kennis, (1979) Effects of budgetary goal characteristics on attitudes and Managements of Performances. The Accounting Review, 54, 707-721.

[16] Mak Yuen Ten (1989) Contingency Fit, Internal Consistency and Financial Performance, Journal of Business Finance \& Accounting, 16 (2), Spring.

\section{Author Profile}

Irma Ibrahim, ME, reveived the magister of economic management from UHAMKA University, Indonesia on 2011. Lecturer in economic management Universitas Muhammadiyah Maluku Utara Ternate, Indonesia. 